\title{
The gamification of work: Lessons from crowdsourcing
}

\author{
Authors: Morschheuser Benedikt \& Hamari Juho
}

\begin{abstract}
The nature of work and management are in flux; work is increasingly distributed, sporadic, community-driven and motivated by constant self-development. Therefore, developments such as sharing economies, crowdfunding and crowdsourcing have emerged as new forms of organizing work and economic coordination. At the same time, increased gaming and gamification of our lives have arrived to address this newly-found yearning for intrinsically motivated work. Therefore, work is increasingly consciously and unconsciously gamified. Crowdsourcing is a frontrunner management domain in employing gamification to positively affect motivation and performance of workers. However, to be able to harness the full potential of gamification, a union of knowledge of interwoven areas of game design, motivational psychology and management is needed. Therefore, in this article, based on the accumulated body of research on gamification in crowdsourcing, we discuss the emerging opportunities and challenges of using gamification in management.
\end{abstract}

Keywords: Gamification, Crowdsourcing, Human Computation, Motivation, Participation, Human resource, work 


\section{Benedikt Morschheuser}

Gamification Group, Tampere University of Technology, Finland

Institute of Information Systems and Marketing, Karlsruhe Institute of Technology, Germany

benedikt.morschheuser@kit.edu

\section{Juho Hamari}

Gamification Group, Tampere University of Technology, Finland

Gamification Group, University of Turku, Finland

Gamification Group, University of Tampere, Finland

juho.hamari@tut.fi

\section{Correspondence:}

Benedikt Morschheuser

Karlsruhe Institute of Technology (KIT)

Fritz-Erler-Straße 23

76131 Karlsruhe

benedikt.morschheuser@kit.edu

T: +49 1773474435 


\section{The gamification of work: Lessons from crowdsourcing}

The increasing ubiquitous interconnectedness based on recent technological developments, such as the Internet and smartphones, has enabled new modes of economic coordination and management to become feasible, such as crowdsourcing (Afuha and Tucci, 2012) and sharing economies (Belk, 2014; Hamari et al., 2016). While in the past, organizations commonly created value within well-defined organizational structures, recent technological advancements have made it feasible to coordinate and employ large groups of Internet users the crowd - in a host of activities of collective value creation (Estellés-Arolas and GonzálezLadrón-de-Guevara, 2012). As a result, more and more organizations now apply crowdsourcing for outsourcing various kinds of work to the crowd rather than using employees or suppliers. The application of crowdsourcing reaches diverse array of domains, which include for example the creation of ideas and innovations (Bayus, 2013; Hutter et al., 2011), the gathering of knowledge, and the creation of user-generated content (Nov, 2007), the solving of complex problems that require creativity and human intelligence (Afuah and Tucci, 2012; Cooper et al., 2010), the annotation of images, text, or video data (Von Ahn and Dabbish, 2008), and even the funding of products (Paschen, 2017; Stemler, 2013). Business analysts expect that $75 \%$ of high-performing enterprises will employ crowdsourcing as part of their value creation by 2018 (Gartner, 2014) and many startups are known whose workforce is primarily based on crowd workers (Tapscott and Williams, 2011). 
In parallel, business analysts also estimate that at least $50 \%$ of all organizations that manage such innovation processes gamifiy their processes (Gartner, 2011) and reviews of literature show that crowdsourcing systems are one of the largest domains employing gamification (Koivisto \& Hamari, 2017; Morschheuser et al., 2017b), that is, organizations seek to make the crowdsourced work activity more like playing a game (Vesa et al., 2017) in order to provide other motives for working than just monetary compensation (Colbert et al., 2016). However, while the new phenomenon seems intuitively appealing, there is little coherent knowledge on the gamification of work and its potential opportunities and challenges. Furthermore, to be able to harness the full potential of gamification, a union of knowledge of interwoven areas of game design, motivational psychology and management is needed. Therefore, in this article, based on the accumulated body of research on gamification in crowdsourcing, we discuss the emerging opportunities and challenges of using gamification in management.

\section{Opportunities}

Traditionally, participants in crowdsourcing approaches - crowdsourcees - are being rewarded via extrinsic incentives, i.e. monetary compensation. However, many studies suggest that crowdsourcees' participation and behaviors are driven by intrinsic aspects of crowdsourcing, such as possibilities for self-development, curiosity, altruism, a sense of competence, satisfaction, and accomplishment when solving crowdsourcing tasks or relatedness with a community of peers (Nov, 2007). Since games are generally perceived as particularly effective in satisfying intrinsic needs (Ryan et al., 2006), designers are increasingly gamifying crowdsourcing systems (Goes et al., 2016; Jung et al., 2010). In other words, designers enrich crowdsourcing approaches with design features from games to address the crowdsourcees' intrinsic needs and make participation in crowdsourcing a similar 
appealing experience as playing a game. When designed appropriately, gamification is believed to help in intrinsic need satisfaction, i.e. feeling competent, feeling of being part of a meaningful group as well as a sense of autonomy (Ryan et al., 2006). Therefore, in addition to possible cost-efficiencies of gamification as a participation incentive, gamification make participation more autotelic possibly more creative.

Various empirical studies confirm that gamification is indeed an effective approach to increase the motivation of (crowd)workers and influence their behaviors, such as the quantitative crowdsourcing participation, the contribution quality and even the long-term engagement (Morschheuser et al., 2017b). Different kinds of implementation of gamification can lead to different motivational effects and behavioral outcomes. For instance, the use of gamification features that invoke competitions among crowdsourcees is a commonly found practice in the gamification of crowdsourcing systems to positively influence the performance of crowdsourcees in monotonous and repetitive crowd (Jung, et al., 2010; Liu, et al., 2013). On the other hand, gamification patterns exist that are able to support the quality of crowdsourcing outcomes or motivate people to work together (Von Ahn and Dabbish, 2008). The versatility of games and the possibility to adapt them to various themes and contexts makes gamification a flexible and manifold design direction. Further, popular examples, such as Waze (a navigation system with real-time, crowd-generated traffic information), Yelp (a crowd-generated world-spanning business directory), Ingress (an augmented reality game with a crowd-generated database of landmarks and public art) or Foldit (a gamified crowdsourcing approach for predicting optimal protein structures and foldings), demonstrate that using gamification in crowdsourcing can be applied in many domains and for various purposes. 
According to the theory of the firm, complicated projects are commonly undertaken in-house (Williamson, 1975). Therefore, crowdsourcing appears as exceptionally unintuitive form of organizing as coordinating a crowdsourcing project can be regarded already complicated in itself. However, it is generally observed that within games, collaboration forms effortlessly and organically. It is this power of games of creating mutual collaborative but also for transforming the coordination cost to the crowdsourcees themselves. Therefore, compared to competitive gamification, cooperative game design not only holds the potential to have people working together seamlessly, but gamification in crowdsourcing also enables further cost effectiveness by reducing costs of coordinating human capital (Morschheuser et al., 2017a).

Besides the support of motivation and participation in crowd work, the onboarding and training of workers is another aspect where the use of gamification can be particularly beneficial. Games are usually complex, challenging and require specific skills. However, game designers have perfected it to educate users complicated tasks in simple and engaging ways by using, for instance, playful tutorials, the successive increase of task complexity aligned with a player's experience, or narratives that can make complicated matters more appealing. Especially in work environments with heterogeneous and difficult tasks, the application of such approaches from games can help to train crowdsourcees in the execution of complex tasks and to keep entry barriers low.

\section{Challenges}

While from an optimistist's perspective, the use of gamification in work places seem to promise productivity and creativity with decreased cost and thus appears as an intuitively 
appealing management strategy, various challenges in applying gamification effectively and meaningfully make gamification a rather complex endeavor as a management practice.

First, gamification and crowdsourcing are both multifaceted phenomena; not all gamification implementations or crowdsourcing projects are similar. There are several types of crowdsourced work (Geiger \& Schader, 2014; Prpić et al., 2015), such as crowdprocessing, crowdrating, crowdcreating or crowdsolving. Moreover, there also are the plethora of different ways to employ gamification (Koivisto \& Hamari 2017). It is rather common that an ignorance of the complexity of both phenomena and the lack of more holistic understanding have resulted in modest results (cf. Landers in this issue). A comprehensive literature review of the existing body of knowledge on gamified crowdsourcing found that crowdsourcing activities can differ dramatically with respect to dimensions of for example homogeneityheterogeneity and individual-team work; so too singular gamification designs range on continuums of e.g. individual-competition-cooperation as well as achievement-immersion based in a similar way as games can. Therefore, practitioners seeking to employ gamification in crowdsourcing should remain mindful about the plethora of options and differential fits between motivational design contra nature of the work being crowdsourced. According to the corpus of literature on gamified crowdsourcing, more monotonous work has more commonly employed competitive and achievement-based gamification implementations, while implementations that seek diverse and creative (e.g. Amabile et al., 1996 on creativity) contributions typically employed more immersive and cooperative gamification designs with a richer set of mechanics (Morschheuser et al., 2017b).

Secondly, individuals all have differing aspirations, preferences, and performance-levels, which can make it inappropriate to employ a monolithic gamification design for any kind of 
system. Successful gamification designs, as a human technology, commonly require a comprehensive understanding of the target group, including the organizational culture (e.g. Barney 1986), goals of the workforce (Latham 2004), the level of proactivity in shaping the work (e.g. Wrzesniewski \& Dutton 2001), and overall personality traits, needs, and motives and precisely designed gamification affordances that match the identified characteristics of the considered users (Hamari et al., 2018). Further, the experience of users with a system and the motivation of individuals not only in short- but also in long-term adds another level of complexity to the design of gamification, which can normally only be counteracted by a continuous monitoring of user-behavior and a repetitive adaptation of implemented gamification features. However, the efforts and costs that are required for realizing such usercentered, never-ending design process can be easily underestimated, especially as the idea of using game features instead of financial incentives appear, at first glance, cost-effective and thus tempting.

Thirdly, satisfying crowdsourcees' intrinsic needs can be regarded as the primary purpose of gamification in crowdsourcing. However, organizations seeking to employ gamification may forget that workers might already be intrinsically motivated without artificial inducement and already immersed in pro-active crafting of their own work (Wrzesniewski \& Dutton 2001). Therefore, gamification may also have the negative potential to deteriorate the healthy composition of existing motivations especially if for example gamification is employed to (e.g. Amabile 1979), for instance, create unwanted competition between people where a productive collaboration already existed. Moreover, games and their design features are commonly used for their hedonic attraction, which can easily whitewash the reputable purpose of a gamified activity, with possible negative effects on the seriousness of the execution of the activity and thus their output quality. An example for such possible negative 
effects of gamification in crowd work is reported by Carlier et al. (2015), who found that a gamified version of a crowdsourcing-based image segmentation systems led to a decrease in the output quality compared to non-gamified crowdsourcing. Consequently, we are convinced that designers and operators of crowdsourcing systems should carefully investigate the motives of crowdsourcees and design gamification reward mechanisms that take different motives into account and reward the quality of contributions (Boons et al., 2015; Hamari et al. 2018; Von Ahn \& Dabbish, 2008).

Fourthly, while majority of the discussion on gamification revolves around the positive psychology (e.g. Seligman et al., 2004) of games and their beneficial impact on human behavior (Koivisto \& Hamari, 2017; Ryan et al., 2006), critics note that gamification possesses the dangers of being used in unethical ways and that gamification can appear as an awry manifestation of the 'true' nature of good games that are commonly regarded as the stem inspiration of gamification (Kim, 2016). Simplistic gamification efforts have been compared to e.g. exploitation ware, dark design patterns, operant conditioning (Skinner 1948), and design that attempts to purposefully target cognitive biases and rational weaknesses (e.g. Simon, 1982 on bounded rationality) in efforts to unfairly benefit others than the users themselves. Thus, applying gamification in labor, including crowdsourced work, we should remain careful and conscious about the ethical dilemma of replacing income with bells and whistles. It is important to strive to develop gamification in ways that can support the intrinsic aspirations, cooperation and self-development also beyond simply increasing the enjoyability of work activities, rather than attempting to myopically change the behavior of people in the short term. 
In sum, while the nature of work is changing and is becoming increasingly digital, distributed, creative and driven by social and intrinsic motivations, gamification promises to be able to provide appropriate incentives for these new forms of value creation. However, since the opportunities of using gamification are as diverse as the nature of games themselves (cf. Deterding in this issue), management scholars and practitioners should not underestimate the complexity of gamifying work environments. Moreover, the ethical consequences and costs of employing gamification in management need to be considered. Even if many studies consistently report positive results of the gamification of work, we lack coherent knowledge about the weaknesses and challenges of gamification. Thus, we hope that this article may act as an anchoring point that encourages scholars and practitioners to further investigate the gamification of work.

\section{References}

Afuah, A., \& Tucci, C. (2012). Crowdsourcing as a solution to distant search. Academy of Management Review, 37(3), 355-375.

Amabile, T. M. (1979). Effects of external evaluation on artistic creativity. Journal of personality and Social Psychology, 37(2), 221.

Amabile, T. M., Conti, R., Coon, H., Lazenby, J., \& Herron, M. (1996). Assessing the work environment for creativity. Academy of management journal, 39(5), 1154-1184.

Barney, J. B. (1986). Organizational culture: can it be a source of sustained competitive advantage?. Academy of management review, 11(3), 656-665.

Bayus, B. L. 2013. Crowdsourcing new product ideas over time: An analysis of the Dell IdeaStorm community. Management Science, 59(1), 226-244.

Belk, R. (2014). You are what you can access: Sharing and collaborative consumption online. Journal of Business Research, 67(8), 1595-1600.

Boons, M., Stam, D., \& Barkema, H. G. (2015). Feelings of pride and respect as drivers of ongoing member activity on crowdsourcing platforms. Journal of Management Studies, 52(6), 717-741. 
Carlier, A., Salvador, A., Cabezas, F., Giro-i-Nieto, X., Charvillat, V., \& Marques, O. (2016). Assessment of crowdsourcing and gamification loss in user-assisted object segmentation. Multimedia Tools and Applications, 23(75).

Colbert, A., Yee, N., George, G. (2016). The digital workforce and the workplace of the future. Academy of Management Journal, 59(3), 731-739.

Cooper, S., Khatib, F., Treuille, A., Barbero, J., Lee, J., Beenen, M., ... Players, F. (2010). Predicting protein structures with a multiplayer online game. Nature, 466(5), 756760.

Estellés-Arolas, E., \& González-Ladrón-de-Guevara, F. (2012). Towards an integrated crowdsourcing definition. Journal of Information Science, 38(2), 189-200.

Gartner (2011). Gartner Says by 2015, More Than 50 Percent of Organizations That Manage Innovation Processes Will Gamify Those Processes. Retrieved from http://www.gartner.com/it/page.jsp?id=1629214

Gartner (2014). Predicts 2015: Sourcing Strategies Shift From 'Built to Last' to 'Built to Adapt. Retrieved from https://www.gartner.com/doc/2925517/predicts--sourcingstrategies-shift.

Geiger, D., \& Schader, M. (2014). Personalized task recommendation in crowdsourcing information systems - Current state of the art. Decision Support Systems, 65, 3-16.

Goes, P. B., Guo, C., \& Lin, M. (2016). Do incentive hierarchies induce user effort? Evidence from an online knowledge exchange. Information Systems Research, 27(3), 497-516.

Hamari, J., Hassan, L., \& Dias, A. (2018). Gamification, quantified-self or social networking? Matching users' goals with motivational technology. User Modelling and User-Adapted Interaction, 28(1), 35-74.

Hamari, J., Sjöklint, M., \& Ukkonen, A. (2016). The sharing economy: Why people participate in collaborative consumption. Journal of the Association for Information Science and Technology, 67(9), 2047-2059.

Hutter, K., Hautz, J., Füller, J., Mueller, J., \& Matzler, K. (2011). Communitition: The Tension between Competition and Collaboration in Community-Based Design Contests. Creativity and Innovation Management, 20(1), 3-21.

Jung, J. H., Schneider, C., \& Valacich, J. (2010). Enhancing the Motivational Affordance of Information Systems: The Effects of Real-Time Performance Feedback and Goal Setting in Group Collaboration Environments. Management Science, 56(4), 724-742.

Kim, T. W. (2016). Gamification of labor and the charge of exploitation. Journal of Business Ethics, (August), 1-13.

Koivisto, J., \& Hamari, J. (2017). The rise of motivational information systems: A review of gamification research. Working paper. 
Latham, G. P. (2004). The motivational benefits of goal-setting. The Academy of Management Executive, 18(4), 126-129.

Liu, D., Li, X., \& Santhanam, R. (2013). Digital Games and Beyond: What happens when players compete? MIS Quarterly, 37(1), 111-124.

Morschheuser, B., Riar, M., Hamari, J., \& Maedche, A. (2017a). How games induce cooperation? A study on the relationship between game features and we-intentions in an augmented reality game. Computers in Human Behavior, 77, 169-183.

Morschheuser, B., Hamari, J., Koivisto, J., \& Maedche, A. (2017b). Gamified crowdsourcing: Conceptualization, literature review, and future agenda. International Journal of Human-Computer Studies, 106, 26-43.

Nov, O. (2007). What motivates Wikipedians? Communications of the ACM, 50(11), 60-64.

Paschen, J. (2017). Choose wisely: Crowdfunding through the stages of the startup life cycle. Business Horizons, 60, 179-188.

Ryan, R. M., Rigby, C. S., \& Przybylski, A. (2006). The motivational pull of video games: A self-determination theory approach. Motivation and emotion, 30(4), 344-360.

Seligman, M. E., \& Csikszentmihalyi, M. (2014). Positive psychology: An introduction. In Flow and the foundations of positive psychology (pp. 279-298). Springer Netherlands.

Simon, H. A. (1982). Models of bounded rationality: Empirically grounded economic reason (Vol. 3). MIT press.

Skinner, B. F. (1948). "Superstition” in the pigeon. Journal of Experimental Psychology, 38(2), 168-172.

Stemler, A. (2013). The JOBS Act and crowdfunding: Harnessing the power - and money of the masses. Business Horizons, 56, 271-285.

Tapscott, D., \& Williams, A. D. (2011). MacroWikinomics: Rebooting business and the world. London: Atlantic Books.

Vesa, M., Hamari, J., Harviainen, J. T., \& Warmelink, H. (2017). Computer Games and Organization Studies. Organization Studies, 38(2), 273-284.

Von Ahn, L., \& Dabbish, L. (2008). Designing games with a purpose. Communications of the ACM, 51(8), 57-67.

Williamson, Oliver E. (1975). Markets and Hierarchies: Analysis and Antitrust Implications. New York: The Free Press.

Wrzesniewski, A., \& Dutton, J. E. (2001). Crafting a job: Revisioning employees as active crafters of their work. Academy of management review, 26(2), 179-201. 


\section{Author Biography}

\section{Dr. Benedikt Morschheuser}

Benedikt Morschheuser is a gamification researcher, associated with the Gamification Group at the Tampere University of Technology and the Institute of Information Systems and Marketing at the Karlsruhe Institute of Technology. His work focuses on the use of gamification in collaborative environments, especially in crowdsourcing systems and online communities. Dr. Morschheuser is author of various scientific publications on the effects of gamification and the designs of gamified information systems, which has been published in internationally scholarly journals such as Computers in Human Behavior, Information and Software Technology or the International Journal of Human-Computer Studies. In the last five years, he invented and designed several gamification approaches for the German automotive and the Swiss finance industry. https://issd.iism.kit.edu/21_126.php

\section{Prof. Dr. Juho Hamari:}

Juho Hamari is a Professor of Gamification and leads the Gamification Group across Tampere University of Technology, University of Turku and University of Tampere. Dr. Hamari has authored several seminal scholarly articles on games and gamification from perspective of consumer behavior, human-computer interaction and information systems science/management. Hamari has received several awards and honours for his research which has been published in a variety of prestigious venues such as Organization Studies, JASIST, IJIM, Computers in Human Behavior, Internet Research, Electronic Commerce Research and Applications, Simulation \& Gaming as well as in books published by e.g. MIT Press. http://juhohamari.com. 